\title{
Expression of AML1-d, a short human AML1 isoform, in embryonic stem cells suppresses in vivo tumor growth and differentiation
}

\author{
Revital Ben Aziz-Aloya ${ }^{1}$, Ditsa Levanon ${ }^{1}$, Heather Karn', \\ Debora Kidron', Dalia Goldenberg', Joseph Lotem ${ }^{1}$, \\ Sylvie Polak-Chaklon ${ }^{3}$ and Yoram Groner ${ }^{1,4}$ \\ 1 Department of Molecular Genetics, The Weizmann Institute of Science, \\ Rehovot, 76100 Israel \\ 2 Department of Pathology, Meir Hospital, Kfar-Saba, Israel \\ ${ }^{3}$ Department of Pathology, Tel Hashomer Hospital, Ramat-Gan, Israel \\ ${ }^{4}$ corresponding author: Department of Molecular Genetics. The Weizmann \\ Institute of Science, Rehovot, 76100 Israel. Tel: 972-8-9343972; \\ e-mail: Ivgroner@weizmann.weizmann.ac.il
}

Received 23.2.98; revised 14.4.98; accepted 15.5.98

Edited by G. Ciliberto

\begin{abstract}
The human AML1 gene encodes a heterodimeric transcription factor which plays an important role in mammalian hematopoiesis. Several alternatively spliced AML1 mRNA species were identified, some of which encode short protein products that lack the transactivation domain. When transfected into cells these short isoforms dominantly suppress transactivation mediated by the full length AML1 protein. However, their biological function remains obscure. To investigate the role of these short species in cell proliferation and differentiation we generated embryonic stem (ES) cells overexpressing one of the short isoforms, AML1-d, as well as cells expressing the full length isoforms $A M L 1-b$ and AML2. The in vitro growth rate and differentiation of the transfected ES cells were unchanged. However, overexpression of AML1-d significantly affected the ES cells' ability to form teratocarcinomas in vivo in syngeneic mice, while a similar overexpression of AML1-b and AML2 had no effect on tumor formation. Histological analysis revealed that the AML1-d derived tumors were poorly differentiated and contained numerous apoptotic cells. These data highlight the pleiotropic effects of AML1 gene products and demonstrate for the first time an in vivo growth regulation function for the short isoform AML1-d.
\end{abstract}

Keywords: AML1 short isoform; ES cells induced teratocarcinomas; altered in vivo differentiation; enhanced apoptosis

Abbreviations: ES, embryonic stem; CBF, core-binding factor; LIF, leukemia inhibitory factor; TCR, t-cell receptor; $M B$, methoxybenzamide; EB, embryoid bodies; EC, embryonal carcinoma; TUNEL, terminal deoxynucleotidyltransferase; dUTP, nick end labeling

\section{Introduction}

The human chromosome 21 acute myeloid leukemia gene, AML1, is frequently rearranged in the leukemia associated translocations $t(8 ; 21), t(3 ; 21)$ and $t(12 ; 21)$, generating different fused proteins (reviewed in Nucifora and Rowley, 1995). In these translocations, transcription of the fusions is mediated by upstream promoter regions that normally regulate the expression of AML1 (Ghozi et al, 1996). AML1 belongs to a gene family of transcription factors sharing high homology with a region of 128 amino acids (a.a.) designated 'runt domain' (RD) present in the Drosophila pair-rule gene runt (reviewed in Kagoshima et al, 1993; Meyers and Hiebert, 1995; Speck and Stacy, 1995; Ito, 1996). In addition to Drosophila runt, the family includes the human genes AML1, AML2 and AML3 and their respective mouse homologues (Speck and Stacy, 1995; Ito, 1996). AML proteins bind DNA as heterodimers formed with the $\beta$ subunit designated corebinding factor $\beta$ (CBF $\beta$ ) (Kagoshima et al, 1993; Speck and Stacy, 1995). The RD contains regions that are involved in binding to the enhancer DNA sequence PyGPyGGT as well as in the interaction with $\operatorname{CBF} \beta$ (Kagoshima et al, 1993; Meyers and Hiebert, 1995; Speck and Stacy, 1995). The transcriptional activation domain of the $\mathrm{AML}$ proteins lies downstream to the RD (Bae et al, 1994; Meyers et al, 1995a; Speck and Stacy, 1995; Tanaka et al, 1995a). The various chimeric AML1 proteins that are formed in $t(8 ; 21)$ and $t(3 ; 21)$ associated leukemias i.e., AML-ETO, AML-EAP, AML-EVI and AML-MDS, lack the transcriptional activation domain, but retain the ability to interact with the core DNA sequence and with $\operatorname{CBF} \beta$, and may thereby block the normal function of AML1 (Frank et al, 1995; Meyers and Hiebert, 1995; Meyers et al, 1995a; Nucifora and Rowley, 1995; 1995a; Ito, 1996; Zent et al. 1996).

AML1 mRNA is expressed at high levels in the thymus, fetal liver (day 12), and bone marrow (erythroblasts and/or myeloblasts) (Satake et al, 1995; Levanon et al, 1996) and in various hematopoietic cell lines (Bae et al, 1993; Tanaka et al, 1995; Levanon et al, 1994,1996). The two promoter regions of $A M L 1$ contain several potential binding sites for hematopoietic transcription factors (Ghozi et al, 1996). In normal blood cells, five size classes (ranging in size from $2-8 \mathrm{~kb}$ ) of AML1 mRNAs were observed (Miyoshi et al, 1991, 1995; Bae et al, 1993; Levanon et al, 1994, 1996). Subsequently, several cDNA species corresponding to various AML1 mRNAs were isolated (Miyoshi et al, 1991, 1995; Nisson et al, 1992; Bae et al, 1993, 1994; Nucifora et al, 1993b; Levanon et al, 1994, 1996; Meyers et al, 1995a; Zhang et al, 1997). Size differences were mainly due to variations in the $5^{\prime}$ and $3^{\prime}$ untranslated regions. However, additional variability was found in the coding region due to the presence of alternatively spliced stop-codon-containing 
exons. This complexity led to production of several isoforms of AML1 proteins that differed at the amino and carboxy termini. Some of them (for example AML1a in Miyoshi et al (1995) or AML1-d and AML1-f in Levanon et al (1996)) lacked the transactivation domain but retained the RD and hence, the ability to bind DNA and to interact with CBF $\beta$ (Bae et al, 1994; Meyers et al, 1995a; Tanaka et al, 1995a; Levanon et al, 1996). Significantly, these isoforms are similar to the AML1 segment in the fused protein AML1-ETO of the $t(8 ; 21)$ translocation and were detected in normal blood (Sacchi et al, 1994; Levanon et al, 1996). Of note, mice heterozygous for a 'knocked in' AML1ETO fusion gene have a severe block in fetal liver hematopoiesis and die in midgestation from hemorrhaging in the central nervous system (Yergeau et al, 1997). Although apparently similar to the phenotype of 'knock out' mice lacking AML1 activity (Okuda et al, 1996; Wang et al, 1996), AML1-ETO mice-derived yolk sac cells could still differentiate in vitro into mature macrophages whereas yolk sac cells from AML1-/- mice could not (Yergeau et al, 1997). This may suggest that at least in vitro, AML1-ETO hematopoietic stem cells retained some hematopoietic capability whereas $\mathrm{AML}-/$ - cells have completely lost it. When the short AML1 isoforms were transfected into cells they dominantly suppressed transactivation mediated by the full length proteins (Meyers et al, 1995a; Tanaka et al, 1995a; Zent et al, 1996), and modulated the transfected cells' ability to differentiate (Tanaka et al, 1995a; Niitsu et al, 1997). Nevertheless, their in vivo biological function remained obscure. To investigate the role of these short species in cell proliferation and differentiation we generated ES cells expressing one of the short isoforms, AML1-d, as well as cells expressing the full length AML1-b and AML2. These ES-AML clones were used to investigate the effect of $A M L 1-d$ on differentiation and tumorigenicity.

\section{Results}

\section{Expression of AML CDNAs in stably transfected CC1.2 ES cells}

Expression of $A M L$ mRNAs in non-transfected undifferentiated ES cells (line CC1.2, Evans and Kaufman, 1981) grown in the presence of leukemia inhibitory factor (LIF), was hardly detected, but became apparent when cells differentiated (Figure 1A). The two more prominent AML1 mRNA species of 8 and $4 \mathrm{~kb}$ (Levanon et al, 1994) were detected, while the $3 \mathrm{~kb}$ mRNA of AML1-d was not seen.

To study the biological effects of the two AML1 isoforms AML1-b and AML1-d and that of AML2, we overexpressed them in CC1.2 ES cells. Clones of ES cells in which expression of these $A M L$ cDNAs was driven by the PGK promoter were established (Figure $2 \mathrm{~A}$ ). $A M L-1 b$ encodes a protein of 452 a.a. including both the $R D$ and C-terminal transactivation domains, and is, therefore, capable of mediating DNA binding and transactivation. AML1-d encodes a shorter isoform of 243 a.a. which binds to the DNA but in contrast to AML1-b, can not transactivate transcription (Bae et al, 1994; Frank et al, 1995; Meyers et al, 1995a; Tanaka et al, 1995a). The third vector, encodes
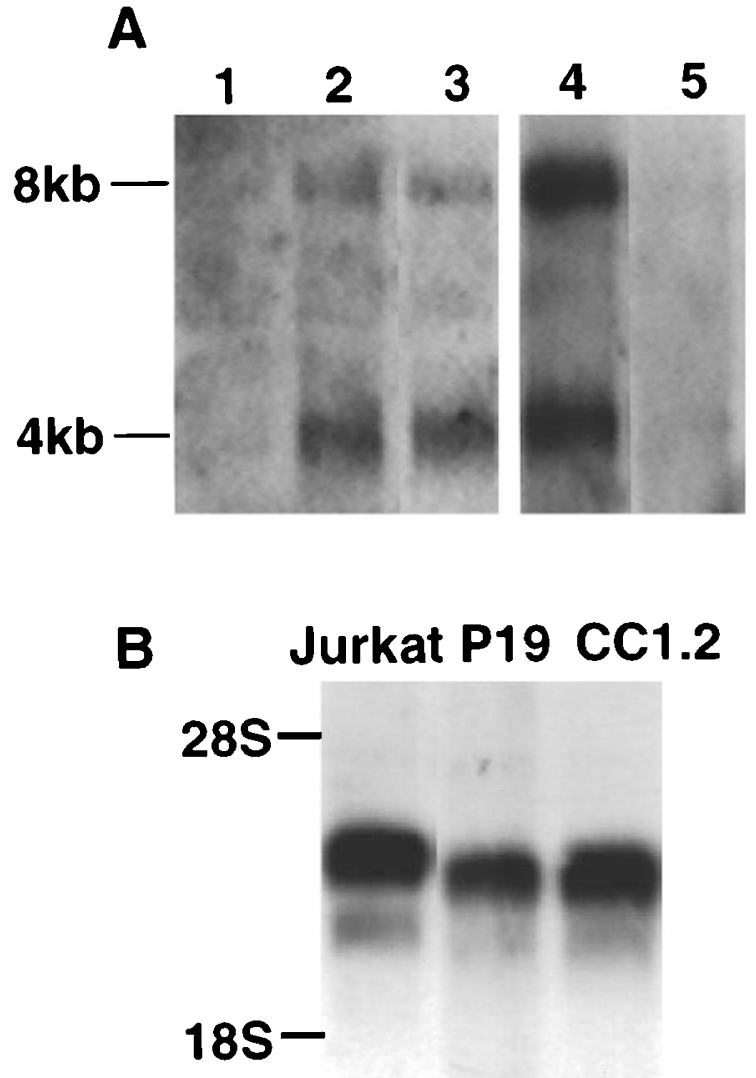

Figure 1 Expression of $\mathrm{AML}$ and $\mathrm{CBF} \beta$ mRNAs in ES cells. (A) Expression of $A M L$ mRNAs in ES during differentiation. Lane 1 ES cells grown in the presence of LIF, Lanes 2 and 3,3 and 14 days following removal of LIF, respectively. Lane 4,5 days with RA $\left(10^{-6} \mathrm{M}\right)$; Lane 5,8 days with 3-MB (2 mM). Lanes 1-3 were probed with mouse $A M L 1$ cDNA and Lanes 4 and 5 were probed with the $3^{\prime}$ coding and UTR regions of AML1. (B) Northern blot analysis of $C B F \beta$ expression. Poly $A^{+} R N A$, prepared from $150 \mu \mathrm{g}$ of RNA of Jurkat, P19 and ES-CC1.2 cells hybridized with a ${ }^{32} \mathrm{P}$-labeled $C B F \beta$ probe. The size difference between mouse and human $\operatorname{CBF} \beta$ is probably due to species differences

the 415 a.a. protein AML2 which contains the RD and transactivation domains (Figure 2A) (Levanon et al, 1994).

Colonies $(30-40)$ of transfected ES cells were selected in medium containing puromycin and collected 8-10 days after electroporation. Northern blot analysis of 12 randomly selected colonies taken from several electroporation experiments, revealed that more than $50 \%$ expressed the vector derived $A M L$ mRNAs (Figure 2B). Of note, the higher molecular weight RNA bands seen in Figure 2B are probably unprocessed RNA species, since they did not appear in preparations of Poly $\mathrm{A}^{+}$RNA. Western blot analysis recorded the level of AML proteins in the transfected ES clones (Figure 2C). Protein bands of the expected size were detected with anti-AML1 antibodies only in the transfected cells (ES-AML), i.e., in nuclear extracts of ES-AML1-b (50 kDa, lane 2) and ES-AML1-d clones (27 kDa, lanes 3 and 4). Using immunostaining, the nuclear localization of AML1-b and AML1-d in the transfected ES clones was confirmed (Figure 2D). The much weaker fluorescent 
signal seen all over the cell in control ES-puro clones was probably non specific since no AML protein was detected in undifferentiated ES cells.

A

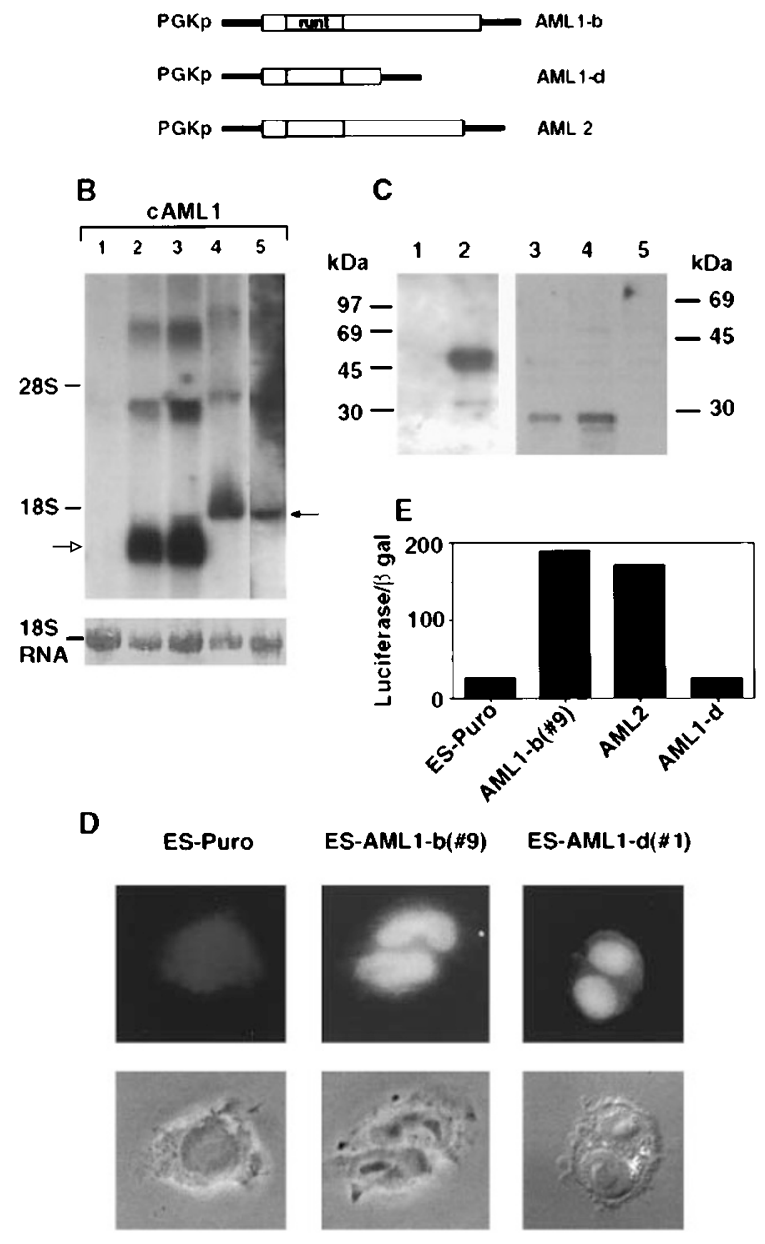

Figure 2 Expression of $A M L$ mRNAs and proteins in stably transfected ES cells. (A) Schematic drawing of the expression vectors harboring AML CDNAs. $A M L$ cDNA expression vectors were constructed by replacing the neo cDNA in a PGK-neo vector (Adra et al, 1987) with the AML1-b, AML1-d or AML2 coding region (Levanon et al, 1996). Expression was driven by the mouse PGK promoter. The PGK poly A signal was added at the $3^{\prime}$ end of the construct. (B) Northern blot analysis of stably transfected ES clones. For each lane $20 \mu \mathrm{g}$ of total RNA were hybridized with $A M L 1-b c D N A$ probe. Electrophoretic migration of $28 \mathrm{~S}$ and $18 \mathrm{~S}$ ribosomal RNA was used as an internal size marker. Lane 1 ES-puro, Lane 2 ES-AML1-d clone \#1; Lane 3 ES-AML1-d clone \#9; Lane 4 ES-AML1- $b$ and lane 5 ES-AML2. The open arrow marks AML1- $d$ mRNA and the dark arrow $A M L 1-b$ and $A M L 2$ mRNAs. $18 \mathrm{~S}$ rRNA is shown as an internal control for loading of RNA per lane. (C) Western blot analysis of ES clones. Nuclear extracts (20 $\mu \mathrm{g} / \mathrm{lane}$ ) of ES-puro (lanes 1 and 5); AML1-b (lane 2), AML1-d clones \#9 and \#1, (lanes 3 and 4) were analyzed with mouse anti AML1 antibody (lanes 1 and 2) or rabbit anti AML1 antibody (lanes 3, 4 and 5). (D) Immunofluorescence labeling of AML1-b and AML1-d proteins in ES cells. Upper panel: Fluorescence image ES-puro, ES-AML1-b and ES-AML1-d cells were treated as described in Materials and Methods. Lower panel: Phasecontrast photomicrographs. (E) Transcription activation through the AML1 DNA binding site by ES-AML clones. Values (mean values of two experiments) represent luciferase activities normalized to $\beta$-gal activity

\section{Transactivation of $\operatorname{TCR} \beta$ enhancer-reporter gene by ES-AML clones}

Mobility shift assays performed to assess the DNA binding activity of AML proteins in the ES-AML clones have shown that both $A M L 1-b$ and $A M L 1-d$ proteins bound to the consensus core DNA sequences (not shown). The $\beta$ subunit $(\mathrm{CBF} \beta)$ plays a major role in increasing the DNA binding activity of AML1 proteins (Speck and Stacy, 1995). $\mathrm{CBF} \beta$ expression in ES cells was analyzed on a Northern blot, high levels of $\operatorname{CBF} \beta$ mRNA were detected in the ES cells, comparable to the level in mouse teratocarcinoma cell line (P19) and to the human T-cell line Jurkat that were used as reference (Figure 1B). Transient transfection with $\mathrm{TCR} \beta$ enhancer vector containing luciferase reporter was used to monitor transactivation mediated by ES-AML cells. Expression of AML1-b or AML2 resulted in an 8-9-fold increase in the levels of TCR $\beta$-luciferase expression (Figure 2E). However, there was no effect of AML1-d expression on TCR $\beta$ enhancer activity (Figure 2E), as previously reported by others (Bae et al, 1994; Meyers et al, 1995a; Tanaka, 1995a).

Taken together, the results of nuclear localization, DNA binding and transactivation demonstrate that the ES-AML clones expressed biologically active AML proteins.

\section{Induction of controlled differentiation programs in the ES-AML clones}

When grown under regular conditions, in the presence of LIF, the ES-AML clones maintained the normal undifferentiated morphology of parental ES cells. To determine whether overexpression of $\mathrm{AML}$ affected the in vitro differentiation program of the ES clones, cultures were exposed to several known differentiation inducing conditions following withdrawal of LIF and monitored by inverted light microscopy (Doetschman et al, 1985; Smith, 1991; Keller, 1995). Under these differentiation-promoting conditions, the ES-AML clones formed embryoid bodies (EBs) that contained differentiated cells of the hematopoietic, endothelial, muscle and neuronal lineages. In the presence of retinoic acid (RA), ES-AML cultures consisted predominantly of large fibroblastic cells. Addition of 3-methoxybenzamide (MB) resulted in a uniform monolayer of epithelial cells. Daily microscopic analysis revealed no significant difference in the differentiation pattern between the parental CC1.2 ES, ES-puro cells and the transfected ES-AML clones. In vitro hematopoietic differentiation was also studied by growing the clones in methylcellulose for 14 days under hematopoietic differentiation conditions as described (Wulf et al, 1993). No significant difference was detected in the number of ES-AML hematopoietic colonies as compared to ES-puro. Overt hemoglobinization manifested by a red color in dark field illumination was seen in all cultures, indicating that the ES clones had undergone hematopoietic differentiation. In addition, expression of several known differentiation markers including c-kit, an early hematopoietic progenitor marker; c-fms, a macrophage marker and embryonic $\beta$ globin ( $\beta \mathrm{H}-1-$ globin) an erythroid marker; were detected by RT-PCR with no significant difference between ES-AML, ES-puro and parental CC1.2 colonies (not shown). 
Taken together, the results of EB formation, RA and 3$M B$ induced differentiation and RT-PCR analyses showed no significant differences in the in vitro differentiation pattern of the ES-AML and ES-puro clones or CC1.2 cells.

\section{Tumorigenicity and in vitro differentiation of ES-AML clones}

The ability of AML proteins to affect tumor development in vivo was tested by subcutaneous injection of ES-AML and ESpuro clones into syngeneic SV129 mice. Under such conditions wild-type ES cells form teratocarcinomas that contain cells of all three germinal layers (Doetschman et al, 1985; Hilberg and Wagner, 1992). Mice injected with control ES-puro clones, as well as with ES-AML clones expressing full length $A M L 1-b$ and AML2, developed tumors within 1418 days after injection. In contrast, a dramatic decrease in the number of tumors was observed when two independently derived ES-AML1-d clones, $d \# 9$ and $d \# 12$ were injected

\section{A}

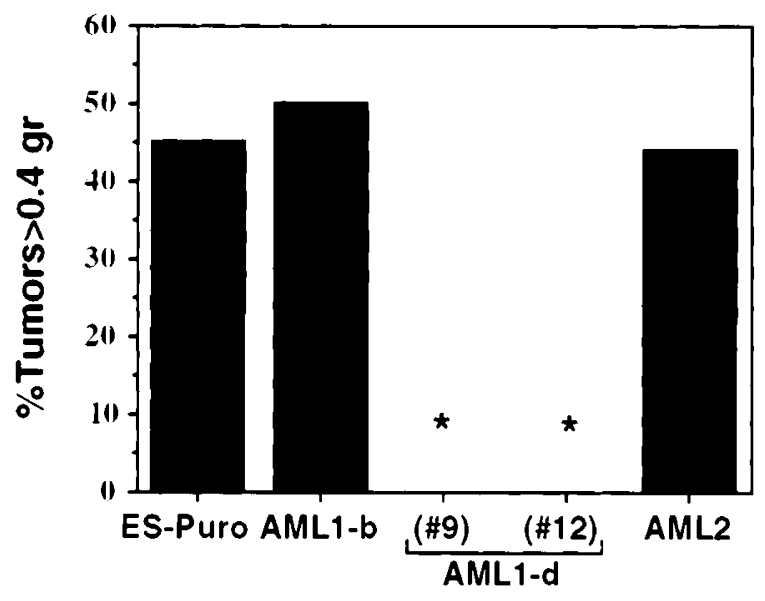

B

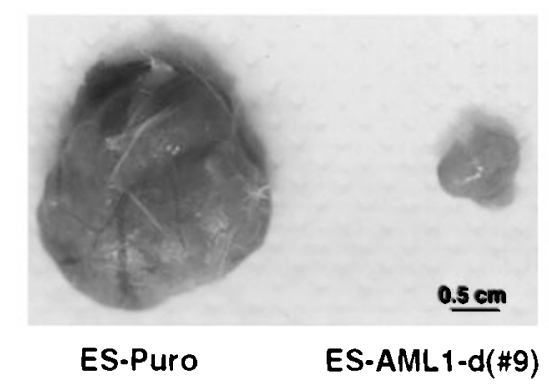

Figure 3 Suppresion of in vivo tumorigenicity of ES cells by overexpression of AML1-d. (A) Syngeneic SV129 mice $(n=8-15)$ were injected subcutaneously with $2 \times 10^{6}$ ES-AML or ES-puro cells in $0.2 \mathrm{ml}$ PBS. Clearly detectable tumors (i.e. $>0.4 \mathrm{gr}$ ) were counted 25 days following injection. $\left(^{*}\right)$ All tumors of AML1-d clones weighed less than $0.4 \mathrm{gr}$. The presented data are of a representative experiment out of the three carried out each with a similar number of mice. (B) Reduced size of tumors generated by ES-AML1-d compared to ES-puro clones. Mice were sacrificed on day 25 following injection and tumors were removed. Depicted are representative tumors from mice injected with ES-puro and ES-AML1-d clone \#9
(Figure $3 \mathrm{~A}$ and $\mathrm{B}$ ). After 25 days, tumors became evident also in mice injected with the ES-AML1-d clones, but these tumors were much smaller than those obtained with ES-puro or ESAML1-b clones (Figure 3B). To further substantiate these results, two additional ES-AML1-d clones were tested: AML1$\mathrm{d}(\# 1)$ and AML1-d(\#22), expressing relatively high (\#1) and low (\#22) levels of AML1-d mRNA. Both showed delayed tumor formation and a smaller size tumors, similar to ESAML1-d clones d\#9 and d\#12 (not shown). Using Northern blot analysis we confirmed that the in vivo grown tumor cells expressed the corresponding AML RNA at a comparable level to that of the injected ES-AML clones. No such mRNAs were detected in the ES-puro derived tumors. The significant decrease in the ability of ES-AML1-d clones to form tumors in vivo, led us to examine their in vitro growth rate. No significant difference between two ES-AML1-d and ES-puro clones was observed (Figure 4). Therefore, the differences in tumor size in vivo were not due to a marked growth deficiency of the ESAML1-d clones as such. The data suggest that ectopic expression of AML1-d, but not AML1-b or AML2, severely abrogated the ability of the ES cells to form teratocarcinomas in syngeneic mice, implying a role of the short AML1 isoforms, that lack transactivation domain, in cell proliferation in vivo.

Histological analysis of several tumors derived from ESpuro, ES-AML1-b, ES-AML2, or AML1-d revealed marked differences in the differentiation pattern between AML1-d tumors and all the others (Figure 5). Tumors derived from ES-puro, ES-AML1-b and AML2 consisted of small nests of undifferentiated embryonal carcinoma (EC) surrounded by differentiated elements of all three germinal layers (Figure $5 A$ and $B$ ). The degree of differentiation varied from very immature cells to mature tissue. By histological criteria

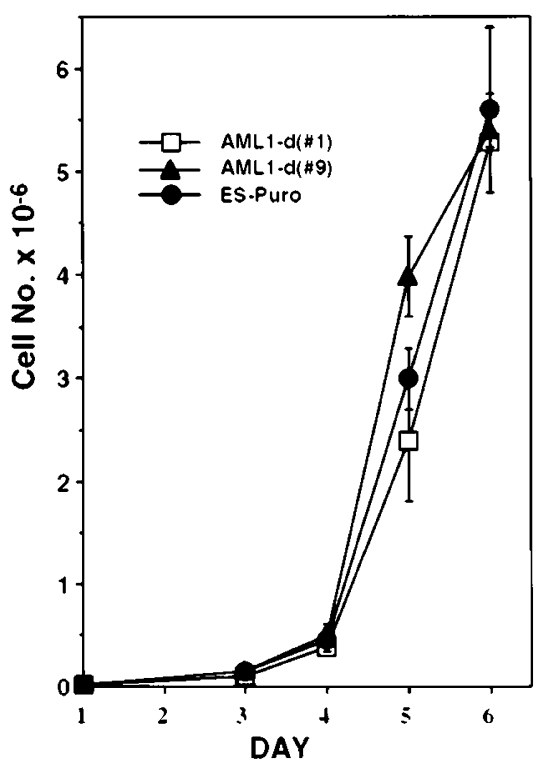

Figure 4 Similar growth rates of ES-puro and ES-AML1-d clones in vitro. Cells $\left(1 \times 10^{5}\right)$ were plated onto tissue culture plates $(6 \mathrm{~cm})$ and counted in hemocytometer daily for 5 days. Each point represents the mean $( \pm S . D$.) of duplicated culture plates 
(Talerman, 1994), such tumors are classified as immature teratomas grade III. In contrast, tumors derived from ESAML1-d clones showed wide areas (approaching 95\% of the section) of homogeneously appearing undifferentiated tumor, occasionally interrupted by small foci of differentiated elements (Figure 5C and D). Tumor cells showed vesicular nuclei, with prominent eosinophilic nucleoli which were centrally located. Also noted were numerous mitotic figures, as well as pyknotic and fragmented nuclei and nuclear debris, suggestive of apoptosis (Figure 5D insert). All in all, the ES-AML1-d tumors can be classified as mixed germ cell tumor with EC and foci of immature teratoma.

The degree of apoptosis in the tumors, was evaluated by the terminal deoxynucleotidyltransferase-mediated dUTP nick end labeling (TUNEL) assay (Figure 6A). Sections of ES-AML1-d tumors contained almost 10 times more TUNEL positive cells than the ES-puro sections (Figure $6 B)$. Of note, TUNEL staining in ES-AML1-d tumors was detected throughout the tumor area, whereas in the ESpuro sections apoptotic cells were closely confined to the undifferentiated regions intermixed within the differentiated area (Figure 6A). The data show that cells within the ESAML1-d tumors undergo accelerated apoptosis, compared to cells in ES-AML1-b or ES-puro tumors. Taken together, the results of reduced tumor size, poorly differentiated tumors and enhanced apoptosis demonstrate that under in vivo conditions overexpression of AML1-d in ES cells caused enhancement of apoptosis which abrogated the
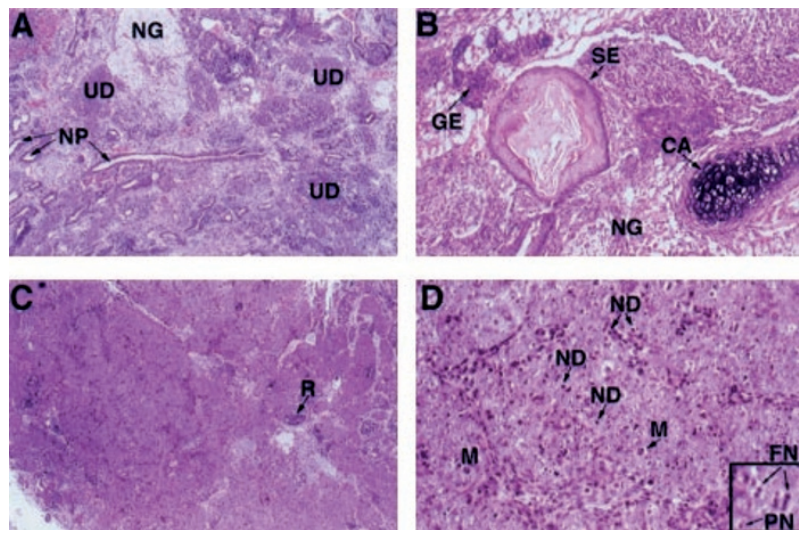

Figure 5 Histological sections of ES-AML1-d and ES-puro teratocarcinomas. ES cells $\left(2 \times 10^{6}\right)$ were injected into SV129 mice and tumors were explanted and processed as described in Materials and Methods. (A and B) ES-puro tumor: (A) Low magnification $(\times 40)$ : Tumor nodule with complex morphologic elements, predominantly showing neuro-epithelial elements (NP) and neuroglial elements (NG). Sporadic small nests of undifferentiated cells (UD) are distributed throughout the tumor. (B) High magnification $(\times 250)$ : Differentiating and differentiated tissues; squamous epithelium (SE), cartilage (CA), glandular elements (GE) and neuroglial elements (NG). (C and D) ESAML1-d(\#9) tumor: (C) Low magnification $(\times 40)$ : Confluent areas of homogeneously appearing undifferentiated tumor cells, focally interrupted by sparse neuroepithelial elements with rosette (R) formation. (D) High magnification $(\times 400)$ : undifferentiated cells with large vesicular nucleus, prominent nucleolus, indistinct cytoplasmic borders, numerous mitotic figures (M) and abundant nuclear debris (ND). insert- $(\times 1000)$ several pyknotic nuclei (PN) and fragmented nuclei (FN) are shown normal growth and differentiation program of the ES cells in vivo.

\section{Discussion}

In the present study we found that stable overexpression of AML1-d in ES cells significantly affected their ability to form teratocarcinomas in syngeneic mice, while similar overexpression of AML1-b and AML2 had no effect on tumor formation. As noted before, the AML1-d isoform belongs to the group of AML1 proteins missing most of the C-terminal amino acids required for transactivation. Several variants of this group were identified which differ from each other in their $\mathrm{N}$ - or C-terminal amino acids (Nucifora et al, 1993b; Miyoshi et al, 1991; Levanon et al, 1996). In contrast to the effect of AML1-d on in vivo tumorigenicity, neither AML1-d nor the full length AML1-b or AML2 affected the in vitro growth rate and differentiation potential of the transfected ES cells. These data highlight the pleiotropic effects of AML1 gene products and demonstrate for the first time an in vivo growth regulation function for the short isoform, AML1-d. It also shows that in vivo the ES cells were exposed to surrounding conditions that

A
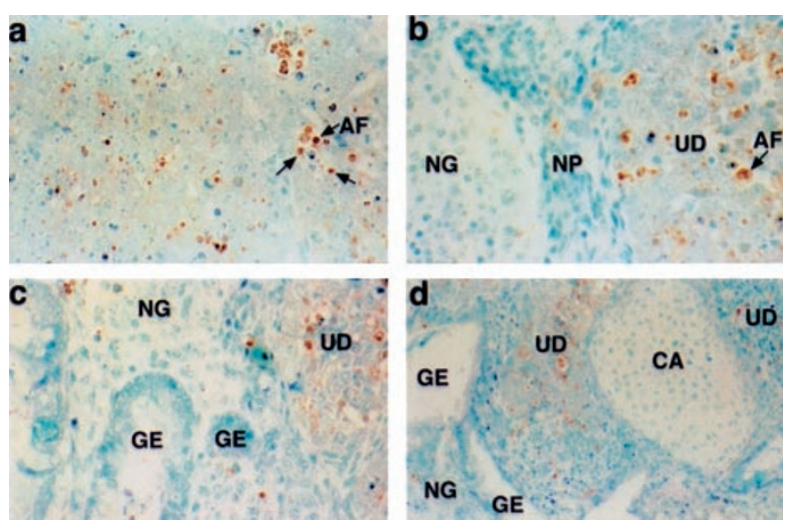

B

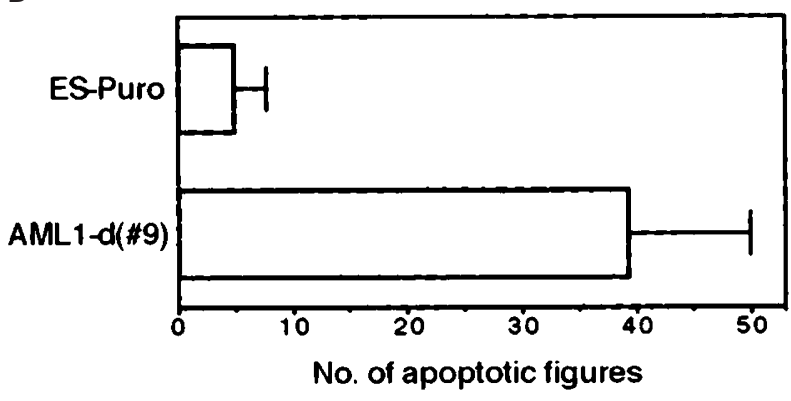

Figure 6 Enhanced apoptosis in ES-AML1-d tumors. (A) Histologic sections, in situ TUNEL method. Apoptotic cells are identified by an intense brown/red staining. (a) ES-AML-1d(\#9) tumor $\times 400$, (b-d) ES-puro tumors, $(b \times 400 ; c$ and $d \times 250)$. AF, apoptotic figures; NG, neuroglial elements; NP, neuroepithelial elements; UD, undifferentiated cells; GE, glandular elements; CA, cartilage. (B) Quantitative analysis of apoptotic cells. Histogram of mean and standard deviation of number of TUNEL positively stained apoptotic figures per microscopic high power field $(n=10)$ in ES-puro and AML1-d (\#9) tumors 
markedly differed from those present in vitro in cell culture. A somewhat analogous observation was previously made in ES cells lacking activity of c-jun. The disruption of both copies of c-jun had no effect on ES cell viability, growth rate or differentiation in vitro but injection into syngeneic mice showed a drastic reduction in tumorigenicity of the c-jun-I- ES cells (Hilberg and Wagner, 1992).

Several lines of evidence suggest that the human $A M L 1$ gene plays crucial roles in hematopoiesis. $A M L 1$ knock out homozygous mice suffer from a block in development of all definitive hematopoietic lineages leading to fetal death by E12.5 (Okuda et al, 1996; Wang et al, 1996). Consistent with this, the list of presently identified AML1 target genes includes a variety of proteins expressed in hematopoietic cells, such as cytokines, cell surface differentiation markers and myeloid specific genes (Reviewed in: Speck and Stacy, 1995). The $A M L 1$ gene is regulated by two promoters (Ghozi et al, 1996) and encodes several protein isoforms that differ at the $\mathrm{N}$ - and C-termini (Miyoshi et al, 1991, 1995; Bae et al, 1993, 1994; Nucifora et al, 1993b; Sacchi et al, 1994; Meyers et al, 1995a; Levanon et al, 1996; Zhang et al, 1997). The various AML1 isoforms may regulate an array of biological events. Indeed, AML1 is involved in control of cell growth and differentiation of both hematopoietic and nonhematopoietic cells (Tanaka et al, 1995a; Kurokawa et al, 1996; Levanon et al, 1996; Niitsu et al, 1997). Reported observations indicated that overexpression of the full length AML1 protein, that contains the Cterminal transactivation domain, causes neoplastic cell transformation in NIH3T3 cells, presumably by enhancing transcription of AML1 target genes (Kurokawa et al, 1996). It is assumed that in these cases AML1 acts as a positive transcription factor, that binds to the consensus core DNA element PyGPyGGT and activates transcription of genes residing in the vicinity of this element. The short isoform AML1a, that did not contain the transactivation domain, did not cause transformation of NIH3T3 cells (Kurokawa et al, 1996). However, other studies indicated that the short isoforms can have biological consequences when overexpressed in cells. For example, the fused protein product AML1-ETO and the short AML1 isoforms can alter AML1dependent transactivation (Reviewed in: Meyers and Hiebert, 1995; Nucifora and Rowley, 1995; Speck and Stacy, 1995; Ito, 1996) and affect differentiation of leukemia cells (Tanaka et al, 1995a; Niitsu et al, 1997), presumably by blocking the normal AML1-dependent transcription activity. Other studies showed that overexpression in Rat1A cells of chimeric AML1/MDS1 protein, that lacks transactivation domain, increased their tumorigenicity in nude mice, whereas expression of AML1/EAP prevented tumor growth (Zent et al, 1996). Of note, the AML1-d isoform described here terminates at a position similar to where the $t(3 ; 21)$ translocation disrupts the AML1 coding region to form the AML1/MDS1 and AML1/EAP fusions (Nucifora et al, 1993a, 1994; Sacchi et al, 1994). Moreover, in the AML1/EAP fusion, EAP adds merely 17 amino acids to the AML1 coding region (Nucifora et al, 1993a; Sacchi et al, 1994) thus generating an AML1-d like protein.

The mechanism by which AML1-d inhibits ES tumorigenicity in vivo remains unknown. Nevertheless, its ability to inhibit tumorigenicity, abrogate differentiation and increase apoptosis in the ES derived tumors, raise the possibility that the AML proteins regulate growth, differentiation and viability functions in the ES derived tumors. The increased apoptosis in the ES-AML1-d derived tumors may be related to the block in fetal hematopoietic development seen in mice heterozygous for knocked in AML1-ETO fusion (Yergeau et al, 1997). Of note, these mice exhibited increased cell death in the vicinity of the blood vessels in hemorrhaging areas (Yergeau et al, 1997). It will be interesting to determine whether overexpression of AML-ETO in ES cells results in a similar reduced tumorigenicity phenotype. The in vivo effects of AML1-d overexpression may be due to competition with the full length isoforms for the DNA-binding site of target genes. In fact, AML1-d can interfere with the activity of all three mammalian AML gene products due to its high affinity for the consensus DNA binding site (Meyers et al, 1995b). Our analysis revealed that expression of AML mRNAs is turned on during in vitro differentiation of ES cells (Figure 1). It is therefore conceivable that the first stages of tumor formation involve expression of the AML genes.

Alternatively, AML1-d may abrogate the in vivo differentiation program, promote apoptosis and inhibit tumorigenicity of ES cells by interacting with other transcription factors that participate in higher order protein-DNA complexes on AML target genes. AML proteins are known to cooperatively interact with Ets, Myb and C/EBP, through adjacent binding sites, to stimulate activity of reporter genes (Reviewed in: Speck and Stacy, 1995; Ito, 1996; Zhang et al, 1996). In addition, AML proteins cooperatively interact with the non DNA binding proteins $\mathrm{CBF} \beta$ and ALY (Reviewed in: Speck and Stacy, 1995; Ito, 1996; Bruhn et al, 1997). Of note, the interactions with Ets, C/EBP and the $\operatorname{CBF} \beta$ are mediated through the runt domain present in the short isoforms (Giese et al, 1995; Speck and Stacy, 1995; Ito, 1996; Zhang et al, 1996). Interestingly, a mutant of the hematopoietic transcription factor PU.1 that lacks transactivation domain, has been shown to efficiently stimulate enhancer activity in the presence of other enhancer binding proteins (Pongubala and Atchison, 1997). It is tempting to speculate that AML1-d, too, may play an architectural role in the interaction with other transcriptional factors, a process for which the transactivation domain is not needed, and thereby activate genes that block differentiation and promote apoptosis. Interestingly, overexpression of PU.1 in erythroleukemia cells inhibits growth and differentiation and induces apoptosis (Yamada et al, 1997). Future work on the activity of the short AML1 isoforms will hopefully allow better elucidation of their biological significance.

\section{Materials and Methods}

\section{Maintenance and differentiation of ES cells in culture}

ES cells, line CC1.2 (Evans and Kaufman, 1981), were cultured at $37^{\circ} \mathrm{C} / 5 \% \mathrm{CO}_{2}$ in an enriched DMEM (DMEM-ES), supplemented with L-Alanine $(8.9 \mathrm{mg} / \mathrm{ml})$, L-Asparagine $(13.2 \mathrm{mg} / \mathrm{ml})$, L-Aspartic acid 
(13.3 $\mathrm{mg} / \mathrm{ml})$, L-Proline $(23 \mathrm{mg} / \mathrm{ml})$, sodium pyruvate $(110 \mathrm{mg} / \mathrm{ml})$, $15 \%$ Fetal Calf Serum (FCS), and $0.1 \mathrm{mM} \beta$-mercaptoethanol. Cells were adapted to grow on gelatinized plates, in the presence of $10^{3} \mathrm{u} /$ $\mathrm{ml}$ leukemia-inhibitory factor (LIF, Gibco BRL) without feeder cells and were examined daily and passaged by trypsinization, every $2-3$ days. To determine the in vitro growth rate, cells $\left(5 \times 10^{4}\right)$ were plated onto $6 \mathrm{~cm}$ tissue culture plates and were trypsinized and counted daily in a hemocytometer. For differentiation in liquid cultures, cells were generally grown in DMEM-ES medium (10\% FCS) in the absence of LIF. $2 \times 10^{6}$ cells were grown in bacteriological plates (for suspension culture) or in gelatin-coated tissue culture plates (for adherent culture) up to 14 days with daily changes of medium. For differentiation in the presence of retinoic acid (RA, $10^{-6} \mathrm{M}$ ) or 3-methoxybenzamide (3$\mathrm{MB}, 2 \mathrm{mM}), 10^{4}$ cells $/ \mathrm{cm}^{2}$ were seeded onto gelatin-coated tissue culture plates in DMEM-ES medium (10\% FCS) supplemented with RA and $10 \mathrm{U} / \mathrm{ml} \mathrm{LIF}$, or with 3-MB and $100 \mathrm{U} / \mathrm{ml}$ LIF as detailed in Smith (1991), and therafter examined daily under the microscope. For differentiation in methyl cellulose we modified the method described in Wulf et al. (1993). Exponentially growing ES cells were adapted to grow in IMDM (Gibco BRL $+15 \%$ FCS). Cells $\left(1.5 \times 10^{3}\right)$ were cultured in $35 \mathrm{~mm}$ bacteriological plates (Falcon) in a final volume of $1.5 \mathrm{ml}$ of $0.8 \%$ methyl cellulose (Fluka) in IMDM, supplemented with $10 \mathrm{mg} / \mathrm{ml}$ Insulin (Sigma), freshly prepared $4.5 \times 10^{-4} \mathrm{M}$ monothioglycerol (Sigma), $0.45 \mathrm{mg} / \mathrm{ml}$ iron saturated transferrin (Boehringer Mannheim), $2 \mathrm{U} / \mathrm{ml}$ erythropoietin (EPO) and $50 \mathrm{mg} / \mathrm{ml}$ ascorbic acid.

\section{Transfection of ES cells, Northern blotting and RT-PCR}

PGK-AML expression vectors were constructed by replacing the neo cDNA cassette in the PGK-neo vector (following digestion by Pstl) (Adra et al, 1987) with AML cDNAs. To generate PGK-AML1-d, the $1.2 \mathrm{~kb}, B s a l-P s t l$ fragment containing the $A M L 1-d$ coding sequence, was used (Levanon et al, 1996, Figure 1). PGK-AML1-b was constructed using the $1.7 \mathrm{~kb}$ Bsal-Xhol fragment of $A M L-1 b$ cDNA (Levanson et al, 1996, Figure 1). For construction of PGK-AML2, a $1.8 \mathrm{~kb}$ EcoRI fragment was isolated from the AML2 cDNA (Levanon et al, 1994, Figure 1). The PGK-Puro plasmid encoding the mouse puromycin resistance gene under the regulation of PGK promoter was a gift from Alan Bradley (University of Cambridge, Cambridge, UK).

AML vectors were cotransfected with PGK-Puro (at a 10:1 molar ratio, total of $25 \mu \mathrm{g} \mathrm{DNA}$ ) into $1 \times 10^{7}$ ES cells by electroporation (BioRad gene pulser, $250 \mathrm{~V}, 500 \mathrm{mF}, 10 \mathrm{~ms}$ time constant). Two days following transfection, growth medium was replaced with fresh medium containing puromycin ( $3 \mu \mathrm{g} / \mathrm{ml}$, Sigma). After 7-10 days, single puromycin-resistant colonies were picked, expanded and analyzed for AML RNA expression by Northern blotting using $20 \mu \mathrm{g}$ total RNA as described (Levanon et al, 1996). For RT-PCR analysis, total RNA was isolated from developing EBs using the RNAzol method (Cinna/ Biotec Laboratories, Inc.). Random primed cDNA was prepared from $1-2 \mu \mathrm{g}$ of total RNA, using MMLV reverse transcriptase (Gibco BRL) in a $20 \mu$ volume. 2-10 $\mu \mathrm{l}$ cDNA was used for PCR amplification. PCR conditions for HPRT, vav, $b H 1$ and $\mathrm{KL}$ were as described by Keller et al (1993) for c-kit (5': $1750-1774$, and 3': 2018-2042), (Qiu et al, 1988) and c-fms (5': $1441-1465$ and $3^{\prime}:$ 1865-1889) (Rothwell and Rohrschneider, 1987), all used at an anealing temperature of $50^{\circ} \mathrm{C}$.

\section{Protein Western blotting and DNA binding analysis}

For whole cell protein extracts, cells were solubilized in RIPA lysis buffer (10 mM Tris $\mathrm{HCl} \mathrm{pH} \mathrm{7.2,} 150 \mathrm{mM} \mathrm{NaCl}, 1 \%$ Triton X-100, 0.1\%
SDS, $1 \%$ deoxycholate (DOC) and $5 \mathrm{mM}$ EDTA), supplemented with protease inhibitors $(0.1 \mathrm{mg} / \mathrm{ml}$ leupeptin), $1.5 \mathrm{mg} / \mathrm{ml}$ pepstatin, $4 \mathrm{mg} /$ $\mathrm{ml}$ aprotinin, $2 \mathrm{mg} / \mathrm{ml}$ chymostatin, $1 \mathrm{mM}$ phenylmethylsulfonyl fluoride and $1 \mathrm{mM}$ sodium orthovanadate).

For nuclear extracts, confluent cultures were grown for $6 \mathrm{~h}$ in the presence of $50 \mu \mathrm{g} / \mathrm{ml}$ of calpain inhibitor I (Boehringer Mannheim). Cell pellets were washed and resuspended in hypotonic buffer $(25 \mathrm{mM}$ Tris $\mathrm{pH} 7.4,2 \mathrm{mM} \mathrm{MgCl}, 0.3 \%$ Triton X-100), kept for $5 \mathrm{~min}$ on ice, and spun down $\left(400 \mathrm{~g}, 8 \mathrm{~min}\right.$, at $\left.4^{\circ} \mathrm{C}\right)$. The pelleted nuclei were resuspended in ice cold lysis buffer $(50 \mathrm{mM}$ Tris $\mathrm{pH} 8,120 \mathrm{mM} \mathrm{NaCl}$, $0.5 \%$ NP- $40,0.05 \%$ SDS) with the above mentioned protease inhibitors, and including $5 \mu \mathrm{g} / \mathrm{ml}$ of calpain inhibitor I. Following 20 min incubation on ice, tubes were centrifuged for $10 \mathrm{~min}$ and the supernatant was used for Western blot analysis. Whole cell or nuclear extract proteins $(20 \mu \mathrm{g})$ were subjected to SDS-gel electrophoresis, blotted onto nitrocellulose membranes and incubated with anti-AML1 antibody. The antibody complex was visualized by incubation with ${ }^{125} \mathrm{I}$-labeled protein $\mathrm{A}$ and exposure to an X-ray film. For electrophoretic mobility shift assay (EMSA), nuclear extracts from the indicated stably transfected ES clones were prepared as described (Haviv et al, 1995). A double stranded oligonucleotide probe, containing a high-affinity AML binding site, was prepared according to Furukawa et al (1990). Binding assays were performed on ice for 30 min under the conditions described in Bae et al (1994).

For assessment of transactivation by $\mathrm{AML}$ proteins in stably transfected ES-AML clones, a reporter construct was used that contained a $550 \mathrm{bp}$ fragment of the mouse TCR $\beta$ enhancer, encompassing three AML binding sites (Krimpenfort et al, 1988) linked to SV40 promoter-luciferase coding region. The reporter gene $(2 \mu \mathrm{g})$ was cotransfected with $\beta$-gal plasmid $(0.2 \mu \mathrm{g})$ (Eustice et al, 1991 ) into $3 \times 10^{5} \mathrm{ES}$ cells (in $35 \mathrm{~mm}$ tissue culture plates, $60-80 \%$ confluent), using lipofectamine (Gibco-BRL). The ratio between luciferase activity in the ES-AML clone and in the ES-puro control clone was used as an indicator of AML-specific transactivation.

\section{AML antibodies and immuno fluorescence staining}

For preparation of anti AML1 antibody, the C-terminal coding region of $A M L 1-b$, downstream from the RD, (885 bp Smal fragment encoding a.a. 190-452), was cloned into a pRSET-C vector (in vitro gene, Netherlands). Recombinant protein was produced and utilized for production of polyclonal antibodies in rabbits and mice. For immuno staining, ES cells were seeded onto tissue culture plates containing gelatinized cover slips. One day later, cells were rinsed in PBS, fixed in $3 \%(\mathrm{v} / \mathrm{v}) \mathrm{N}$. Paraformaldehyde in PBS for $20 \mathrm{~min}$ at $37^{\circ} \mathrm{C}$, and permeabilized with $0.25 \%$ Triton $X-100$, for $5 \mathrm{~min}$, at room temperature (RT). Blocking of non specific binding was conducted with $5 \%(\mathrm{v} / \mathrm{v})$ normal goat serum (Gibco BRL) and $1 \mathrm{mg} / \mathrm{ml}$ of bovine serum albumin (Sigma, USA) for $1 \mathrm{~h}$ at RT. Cells were then incubated with the primary antisera (1:100 in a blocking solution) for $1 \mathrm{~h}$ at RT, rinsed three times in PBS and incubated with Lissamine Rhodamine (LRSC)-conjugated goat anti mouse IgG, or goat anti rabbit IgG (Jackson Laboratories) for $1 \mathrm{~h}$ at RT. Following washing in PBS, coverslips were mounted on microscope slides with $50 \%$ glycerol in PBS (w/w), and cells were visualized and photographed with a fluorescence microscope.

\section{Tumorigenicity assay and in situ detection of apoptosis}

SV129 mice (Jackson Laboratories) (5-6 weeks old males) were injected subcutaneously with $2 \times 10^{6}$ cells in $0.2 \mathrm{ml}$ PBS. Mice were examined daily for tumor formation. Tumors were excised at different 
times after cell inoculation, fixed in $4 \%$ buffered formalin for $24 \mathrm{~h}$ and entirely submitted for histological processing. Four $\mu \mathrm{m}$ thick sections were prepared and stained with Hematoxylin and Eosin (H\&E). The degree of apoptosis was determined by the TUNEL (Terminal deoxynucleotidyltransferase-mediated dUTP Nick End Labeling) procedure (Gavrielli et al, 1992). The ApoTag in situ apoptosis detection kit (Oncor) was used according to manufacturer's instructions. The degree of apoptosis was quantified by counting the number of positively stained cells per high power field (HPF) in 10 HPFs.

\section{Acknowledgements}

This work was supported by grants from the Cooperation Program in Cancer Research of the Deutsches Krebsforschungszentrum (DKFZ) and Israel's Ministry of Science (MOS), the National Institute of Health (USA); the Weizmann Institute's Forchheimer Center of Molecular Genetics; Mr. Bernard Sabrier, Geneva (Switzerland) and the Shapell family biomedical research foundation at the Weizmann Institute.

\section{References}

Adra CN, Boer PH and McBurney MV (1987) Cloning and expression of the mouse pgk-1 gene and the nucleotide sequence of its promoter. Gene 60:65-74

Bae S-C, Ogawa E, Maruyama M, Oka H, Satake M, Shigesada K, Jenkins NA, Gilbert DJ, Copeland NG and Ito Y (1994) PEBP2aB/Mouse AML1 consists of multiple isoforms that possess differential transactivation potentials. Mol. Cell. Biol. 14 $3242-3252$

Bae S-C, Yamaguchi-Iwai Y, Ogawa E, Maruyama M, Inuzuka M, Kagoshima H, Shigesada K, Satake M and Ito Y (1993) Isolation of PEBP2 $\alpha B$ cDNA representing the mouse homolog of human acute myeloid leukemia gene, AML1. Oncogene 8: 809-814

Bruhn L, Munnerlyn A and Grosschedl R (1997) ALY, a context-dependent coactivator of LEF-1 and AML-1, is required for TCRa enhancer function. Genes \& Develop. 11: $640-653$

Doetschman TC, Eistetter H, Katz M, Schmidt M and Kemler R (1985) The in vitro development of blastocyst-derived embryonic stem cell lines: formation of visceral yolk sac, blood islands and myocardium. J. Embryol. Exp. Morph. 87: $27-45$

Eustice DC, Feldman PA, Colberg-Poley AM, M BR and Neubauer RH (1991) A sensitive method for the detection of b-galactosidase in transfected mammalian cells. BioTechniques 11: 739-742

Evans MJ and Kaufman MH (1981) Establishment in culture of pluripotential cells from mouse embryos. Nautre 292: 154-156

Frank R, Zhang J, Uchida H, Meyers S, Hiebert SW and S Nimer D (1995) The AML1/ ETO fusion protein blocks transactivation of the GM-CSF promoter by AML1B. Oncogene 11: 2667-2674

Furukawa K, Yamaguchi Y, Ogawa E, Shigesada K, Satake M and Ito Y (1990) A ubiquitous repressor interacting with an F9 cell-specific silencer and its functional suppression by differentiated cell-specific positive factors. Cell Growth Differ. 1: 135-147

Gavrieli Y, Sherman Y and Ben-Sasson SA (1992) Identification of programmed cell death in situ via specific labeling of nuclear DNA fragmentation. J. Cell Biol. 119: 493-501

Ghozi MC, Bernstein Y, Negreanu V, Levanon D and Groner Y (1996) Expression of the human acute myeloid leukemia gene $A M L 1$ is regulated by two promoter regions. Proc. Natl. Acad. Sci. USA 93: 1935-1940

Giese K, Kingsley C, Kirshner JR and GrosschedI R (1995) Assembly and function of a TCRa enhancer complex is dependent on LEF-1-induced DNA bending and multiple protein-protein interactions. Genes \& Develop. 9: 995-1008

Haviv I, Vaizel D and Shaul $Y$ (1995) The X protein of hepatitis B virus coactivates potent activation domains. Mol. Cell. Biol. 15: 1079-1085

Hilberg F and Wagner EF (1992) Embryonic stem (ES) cells lacking functional c-jun: consequences for growth and differentiation, AP-1 activity and tumorigenicity. Oncogene 7: 2371-2380
Ito $Y$ (1996) Structural alterations in the transcription factor PEBP2/CBF linked to four different types of leukemia. J. Cancer Res. Clin. Oncol. 122: 266-274

Kagoshima H, Shigesada K, Satake M, Ito Y, Miyoshi H, Ohki M, Pepling M and Gergen P (1993) The runt domain identifies a new family of heteromeric DNAbinding transcriptional regulatory proteins. Trend. Genet. 9: 338-341

Keller G, Kennedy M, Papayannopoulou T and Wiles MV (1993) Hematopoietic commitment during embryonic stem cell differentiation in culture. Mol. Cell. Biol. 13: $473-486$

Keller GM (1995) In vitro differentiation of embryonic stem cells. Curr. Opin. Cell Biol. 7: $862-869$

Krimpenfort P, Jong RD, Uematsu Y, Dembic Z, Ryser S, Boehmer HV, Steinmetz M and Berns A (1988) Transcription of T cell receptor beta-chain genes is controlled by a downstream regulatory element. EMBO J. 7: 745-750

Kurokawa M, Tanaka T, Tanaka K, Ogawa S, Mitani K, Yazaki Y and Hirai H (1996) Overexpression of the AML1 proto-oncoprotein in NIH3T3 cells leads to neoplastic transformation depending on DNA-binding and transactivational potencies. Oncogene 12: 883-892

Levanon D, Bernstein Y, Negreanu V, Ghozi MC, Bar-Am I, Aloya R, Goldenberg D, Lotem J and Groner Y (1996) A large variety of alternatively spliced and differentially expressed mRNAs are encoded by the human acute myeloid leukemia gene AML1. DNA and Cell Biol. 15: 175-185

Levanon D, Negreanu V, Bernstein Y, Bar-Am I, Avivi L and Groner Y (1994) AML1, AML2, and AML3, the human members of the runt domain genefamily; cDNA structure, expression and chromosomal localization. Genomics 23: $425-432$

Meyers S and Hiebert SW (1995) Indirect and direct disruption of transcriptional regulation in cancer: E2F and AML-1. Crit. Rev. Eukaryot. Gene Exp. 5: 365-383

Meyers S, Lenny $N$ and Hiebert SW (1995a) The $t(8 ; 21)$ fusion protein interferes with AML-1B-dependent transcriptional activation. Mol. Cell. Biol. 15: $1974-1982$

Meyers S, Lenny N, Sun W-H and Hiebert SW (1995b) AML-2 is a potential target for the $t(8 ; 21)$ fusion protein in myeloid cells. Blood $86: 38$ a

Miyoshi H, Ohira M, Shimizu K, Mitani K, Hirai H, Imai T, Yokoyama K, Soeda E and Ohki M (1995) Alternative splicing and genomic structure of the AML1 gene involved in acute myeloid leukemia. Nucl. Acid Res. 23: 2762-2769

Miyoshi H, Shimizu K, Kozu T, Maseki N, Kaneko Y and Ohki M (1991) t(8;21) breakpoints on chromosome 21 in acute myeloid leukemia are clustered within a limited region of a single gene, AML1. Proc. Natl. Acad. Sci. USA 88: 1043110434

Niitsu N, Yamamoto-Yamaguchi Y, Miyoshi H, Shimizu K, Ohki M, Umeda M and Honma Y (1997) AML1a but not AML1b inhibits erythroid differentiation induced by sodium butyrate and enhances the megakaryocytic differentiation of K562 leukemia cells. Cell Growth \& Diff. 8: $319-326$

Nisson PE, Watkins PC and Sacchi N (1992) Transcriptionally active chimeric gene derived from the fusion of the AML1 gene and a novel gene on chromosome 8 in $\mathrm{t}(8 ; 21)$ leukemic cells. Cancer Genet. Cytogenet. 63: 81-88

Nucifora G, Begy CR, Erickson P, Drabkin HA and Rowley JD (1993a) The 3;21 translocation in myelodysplasia results in a fusion transcript betwen the AML1 gene and the gene for EAP, a highly conserved protein associated with the Epstein-Barr virus small RNA EBER1. Proc. Natl. Acad. Sci. USA 90: 77847788

Nucifora G, Begy CR, Kobayashi H, Roulston D, Claxton D, Pedersen-Bjergaard J, Parganas E, Ihle JN and Rowley JD (1994) Consistent intergenic splicing and production of multiple transcripts between AML1 and 21q22 and unrelated genes at $3 q 26$ in (3;21)(q26;q22) translocations. Proc. Natl. Acad. Sci. USA 91: 40044008

Nucifora G, Birn DJ, Espinosa III R, Erickson P, Le Beau MM, Roulston D, McKeithan TW, Drabkin $\mathrm{H}$ and Rowley JD (1993b) Involvement of the AML1 gene in the $t(3 ; 21)$ in therapy-related leukemia and in chronic myeloid leukemia in blast crisis. Blood 81: 2728-2734

Nucifora G and Rowley JD (1995) AML1 and the 8;21 and 3;21 translocations in acute and chronic myeloid leukemia. Blood 86: 1-14

Okuda T, Deursen JV, Hiebert SW, Grosveld G and Downing JR (1996) AML1, the target of multiple chromosomal translocations in human leukemia, is essential for normal fetal liver hematopoiesis. Cell 84: $321-330$

Pongubala JR and Atchison ML (1997) PU.1 can participate in an active enhancer complex without its transcriptional activation domain. Proc. Natl. Acad. Sci. USA 94: $127-132$ 
Qiu F, Ray P, Brown K, Barker PE, Jhanwar S, Ruddle FH and Besmer P (1988) Primary structure of c-kit: relationship with the CSF-1/PDGF receptor kinase family-oncogenic activation of v-kit involves deletion of extracellular domain and C terminus. EMBO J. 7: 1003-1011

Rothwell VM and Rohrschneider LR4 (1987) Murine c-fms cDNA: cloning, sequence analysis and retroviral expression. Oncogene Res. 1: 311-324

Sacchi N, Nisson PE, Watkins PC, Faustinella F, Wijsman J and Hagemeijer A (1994) AML1 fusion transcripts in $t(3 ; 21)$ positive leukemia: Evidence of molecular heterogeneity and usage of splicing sites frequently involved in the generation of normal AML1 transcripts. Genes, Chrom. Cancer 11: 226-236

Satake M, Nomura S, Yamaguchi-Iwai Y, Takahama Y, Hashimoto Y, Niki M, Kitamura $Y$ and Ito $Y$ (1995) Expression of the runt domain-encoding PEBP2a genes in T cells during thymic development. Mol. Cell Biol. 15: 1662-1670

Smith AG (1991) Culture and differentiation of embryonic stem cells. J. Tiss. Cult. Meth. 13: 89-94

SpeckNA and Stacy T (1995) A new transcription factor family associated with human leukemias. Crit. Rev. Eukaryot. Gene Exp. 5: 337-364

Talerman A (1994) Germ cell tumors of the ovary. In RJ Kurman, ed Blaustein's pathology of the female genital tract, (New York: Springer-Verlag press); pp. $850-896$

Tanaka K, Tanaka T, Ogawa S, Kurokowa M, Mitani K, Yazaki Y and Hirai H (1995) Increased expression of AML1 during retinoic-acid-induced differentiation of U937 cells. Biochem. Biophys. Res. Com. 211: 1023-1030

Tanaka T, Tanaka K, Ogawa S, Korokawa M, Mitani K, Nishida J, Shibata Y, Yazaki Y and Hirai H (1995a) An acute myeloid leukemia gene, AML1, regulates hemopoietic myeloid cell differentiation and transcriptional activation antagonistrically by two alternative spliced forms. EMBO J. 14: 341-350
Wang Q, Stacy T, Binder M, Mari'n-Padilla M, Sharpe AH and Speck NA (1996) Disruption of the cbfa2 gene causes necrosis and hemorrhaging in the central nervous system and blocks definitive hematopoiesis. Proc. Natl. Acad. Sci. USA 93: $3444-3449$

Wulf GM, Adra CN and Lim B (1993) Inhibition of hematopoietic development from embryonic stem cells by antisense vav RNA. EMBO J. 12: 5065-5074

Yamada T, Kondoh N, Matsumoto M, Yoshida M, Maekawa A and Oikawa T (1997) Overexpression of PU.1 induces growth and differentiation inhibition and apoptotic cell death in murine erythroleukemia cells. Blood 89: 1383-1393

Yergeau DA, Hetherington CJ, Wang Q, Zhang P, Sharpe AH, Binder M, MartinPadilla M, Tenen DG, Speck NA and D-E Z (1997) Embryonic lethality and impairment of haematopoiesis in mice heterozygous for an AML1-ETO fusion gene. Nature Genetics 15: 303-306

Zent CS, Mathieu C, Claxton DF, Zhang D-E, Tenen DG, Rowley JD and Nucifora G (1996) The cimeric genes AML1/MDS1 and AML1/EAP inhibit AML1b activatin at the CSF1R promoter, but only AML1/MDS1 has tumor-promoter properties. Proc. Natl. Acad. Sci. USA 93: $1044-1048$

Zhang D-E, Hetherington CJ, Meyers S, Rhoades KL, Larson CJ, Chen H-M, Hiebert SW and Tenen DG (1996) CCAAT enhancer-binding protein (C/EBP) and AML1 $(\mathrm{CBF} \alpha 2)$ synergistically activate the macrophage colony-stimulating factor receptor promoter. Mol. Cell. Biol. 16: 1231-1240

Zhang Y-W, Bae S-C, Huang G, Fu Y-X, Lu J, Ahn M-Y, Kanno Y, KannoT and Ito Y (1997) A novel transcript encoding an N-terminally truncated AML1/PEBP2 $\alpha B$ protein interferes with transactivation and blocks granulocytic differentiation of 32Dc13 myeloid cells. Mol. Cell. Biol. 17: 4133-4145 